\title{
Restriction fragment differential display of pediocin-resistant Listeria monocytogenes 412 mutants shows consistent overexpression of a putative $\beta$-glucoside-specific PTS system
}

\author{
Anne Gravesen, ${ }^{1}$ Peter Warthoe, ${ }^{2}$ Susanne Knøchel ${ }^{1}$ \\ and Kenneth Thirstrup ${ }^{2}$
}

Author for correspondence: Anne Gravesen. Tel: +45 3528 3272. Fax: +45 35283231.

e-mail: alg@kvl.dk

1 Department of Dairy and Food Science, The Royal Veterinary and Agricultural University, Rolighedsvej 30, DK-1958 Frederiksberg C, Denmark

2 Display Systems Biotech, Lersø Parkallé 40, DK-2100 Copenhagen, Denmark

\begin{abstract}
Pediocin PA-1, which is a bacteriocin produced by lactic acid bacteria, has potential as a biopreservative of food. However, such use may lead to the development of resistance in the target organism. Gene expression in two independent pediocin-resistant mutants of Listeria monocytogenes 412 was compared to the original isolate by restriction fragment differential display PCR (RFDD-PCR). This method amplifies CDNA restriction fragments under stringent PCR conditions, enabled by the use of specific primers complementary to ligated adaptor sequences. RFDD-PCR was very well suited for analysis of listerial gene expression, giving reproducible PCR product profiles. Three gene fragments having increased expression in both resistant mutants were identified. All three had homology to components of $\beta$ glucoside-specific phosphoenolpyruvate-dependent phosphotransferase systems (PTS), one fragment having homology to enzyme II permeases, and the two others to phospho- $\beta$-glucosidases. Overexpression of the putative PTS system was consistently observed in $\mathbf{1 0}$ additional pediocin-resistant mutants, isolated at different $\mathrm{pH}$, salt content and temperature. The results suggest that RFDD-PCR is a strong approach for the analysis of prokaryotic gene expression and that the putative $\beta$-glucoside-specific PTS system is involved in mediating pediocin resistance.
\end{abstract}

Keywords: restriction fragment differential display, Listeria monocytogenes, pediocin resistance, phosphoenolpyruvate-dependent phosphotransferase system, bacteriocin

\section{INTRODUCTION}

Biopreservation has been introduced as a potentially efficient, consumer-friendly, supplementary safety measure in controlling the human pathogen Listeria monocytogenes in food. One of the mechanisms of biopreservation is the antimicrobial effect of bacteriocins, of which the two most widely used and best characterized are pediocin and nisin. Bacteriocins are produced by a variety of lactic acid bacteria, representing a natural, diverse source for preservation of

Abbreviations: DD, differential display; PTS, phosphoenolpyruvatedependent phosphotransferase system; RFDD, restriction fragment differential display.

The EMBL accession numbers for the sequences reported in this paper are AJ251202, AJ251203 and AJ251204. different types of food. A major concern, however, is the possibility of resistance development.

Bacteriocins are small, cationic, amphiphilic peptides that insert into and form pores in the cell membrane of target micro-organisms, similar to defence peptides produced by many other organisms including mammals, plants and insects (Nissen-Meyer \& Nes, 1997). Pore formation by nisin and other lanthionine-containing bacteriocins is a dynamic, multi-step process (reviewed by Sahl \& Bierbaum, 1998) and the antimicrobial effect is suggested to depend on the size and lifetime of the pores.

Many antilisterial bacteriocins are homologous, constituting the class IIa or pediocin-like family (Ennahar $e t$ al., 1999). The mode of action of these bacteriocins, 
though not as well characterized as for nisin, is believed to be a similar mechanism. There is some controversy regarding the involvement of a membrane protein receptor in class IIa pore formation. Although pediocin PA-1 caused leakage from lipid vesicles derived from $L$. monocytogenes (Chen et al., 1997), non-lipid components increased the sensitivity of pediococcal vesicles and cells (Chikindas et al., 1993). Thus, it seems that for pediocin (Montville \& Chen, 1998) as well as for nisin (Brötz et al., 1998), a receptor or docking molecule is not absolutely required but can enhance or facilitate pore formation.

It is conceivable that any physiological change retarding pore formation or enhancing membrane repair would enhance survival and resistance development. Accordingly, increased nisin tolerance in Listeria has been related to cell-wall changes reducing accessibility (Davies et al., 1996; Maisnier-Patin \& Richard, 1996), and cell-membrane changes reducing sensitivity of the target (Ming \& Daeschel, 1995; Mazzotta \& Montville, 1997; Verheul et al., 1997; Goulhen et al., 1998). Crandall \& Montville (1998) proposed a model incorporating these effects. Only limited information is available concerning resistance to the pediocin-like bacteriocins. Transposon inactivation of the alternative transcription factor $\sigma^{54}$ conferred resistance to the class IIa bacteriocin mesentericin Y105 in L. monocytogenes (Robichon et al., 1997). Such a mutation would be expected to confer pleiotropic phenotypes, as observed in other organisms (Kustu et al., 1989).

Our objective is to identify the genetic basis of resistance in L. monocytogenes to pediocin PA-1, one of the best characterized bacteriocins of this family. By a differential display-based method, we compared the RNA expressed by pediocin-resistant and -sensitive L. monocytogenes strains. Since the development of the original differential display PCR (DD-PCR) technique (Liang \& Pardee, 1992), where short 10-mer arbitrary primers were used to amplify cDNA synthesized from sample RNA, numerous articles have described the usefulness of this technology for the identification of differentially expressed genes. However, some of the limitations in DD-PCR, such as the restriction to visualization of the 3' end of the transcripts only, low annealing temperature during PCR amplification and a high number of false positives (Debouck, 1995), have encouraged the development of new and improved techniques. Furthermore, the original method displays polyadenylated transcripts and can therefore only be applied to eukaryotic RNA.

The related RNA arbitrarily primed PCR or arbitrarily primed PCR techniques have been employed in prokaryotes (Kullen \& Klaenhammer, 1999; Shepard \& Gilmore, 1999; Fleming et al., 1998; Abu \& Pederson, 1996). These methods rely on arbitrary primers for cDNA synthesis and/or subsequent amplification, and are therefore subject to the poorer reproducibility conferred by low-stringency PCR conditions. Suitable primers have to be designed from a statistical evaluation of coding genomic sequences (Fislage et al., 1997) and many random primers are required to cover the whole bacterial genome.

We have developed the so-called restriction fragment differential display PCR (RFDD-PCR) which is a variation of the cDNA amplified fragment length polymorphism DD technique originally described by Bachem et al. (1996). The technology is based on digesting cDNA with endonucleases followed by adaptor ligation and PCR amplification with specific primers at high-stringency PCR conditions. Thus the method is not limited to polyadenylated transcripts, but can be applied equally well to both eukaryotic and prokaryotic systems.

The results presented here show that RFDD-PCR is a very efficient method for the analysis of bacterial gene expression. Consistent overexpression of one operon was observed in strains having developed pediocin resistance, indicating that this operon, encoding a putative $\beta$-glucoside-specific phosphoenolpyruvate-dependent phosphotransferase system (PTS), is involved in mediating pediocin resistance.

\section{METHODS}

Bacterial strains and growth conditions. L. monocytogenes 412 was obtained from the Danish Meat Research Institute (Roskilde, Denmark). The two pediocin-resistant mutants, $L$. monocytogenes 412P and 412NP, were selected from the wildtype strain and a nisin-tolerant derivative, respectively, on tryptic soya agar (Oxoid) supplemented with $6400 \mathrm{AU}$ pediocin PA-1 ml-1 (Rasch \& Knøchel, 1998) with $\mathrm{pH}$ adjusted to 6.5 , at $30^{\circ} \mathrm{C}$. The strains were cultured in brain heart infusion broth (Difco) with $\mathrm{pH}$ adjusted to 6.5 at $30^{\circ} \mathrm{C}$ without agitation.

RNA purification. For RFDD-PCR template synthesis, RNA was purified from $10 \mathrm{ml}$ culture in late exponential growth phase $\left(\mathrm{OD}_{600} 0 \cdot 6\right)$ by the method of Arnau \& Sørensen (1997). For Northern hybridization, cells from $3 \mathrm{ml}$ culture were lysed with a Fast Prep FP120 shaker (Savant Instruments) at $4.0 \mathrm{~m}$ $\mathrm{s}^{-1}$ for $40 \mathrm{~s}$ with $300 \mathrm{mg}$ glass beads (106 microns and finer, Sigma-Aldrich), and RNA was purified with the RNeasy Mini kit (Qiagen).

RFDD-PCR. The analysis was carried out as described in detail in the protocol from the displayPROFILE kit developed by Display Systems Biotech. Briefly, $500 \mathrm{ng}$ total RNA was reverse-transcribed using a randomized octamer primer, $\mathrm{N}_{8}$ (DNA Technology) and 100 units displayReverse (Display Systems Biotech) in $25 \mu \mathrm{l}$ volume. The reaction was incubated at $42{ }^{\circ} \mathrm{C}$ for $2 \mathrm{~h}$. For second-strand synthesis, a $50 \mu \mathrm{l} \mathrm{mix}$ consisting of buffer, dNTPs, 12 U DNA Polymerase I (Display Systems Biotech), and $0 \cdot 8 \mathrm{U}$ RNase H (Display Systems Biotech) was added. The reaction mixture was incubated at $16{ }^{\circ} \mathrm{C}$ for $2 \mathrm{~h}$ and subsequently phenol/chloroform extracted, precipitated by ethanol and dissolved in $20 \mu \mathrm{l} \mathrm{H}_{2} \mathrm{O}$. Ten microlitres of cDNA was checked on an agarose gel for cDNA smear between 100 and $2000 \mathrm{bp}$.

The remaining $10 \mu \mathrm{l} \mathrm{cDNA}$ was digested with TaqI endonuclease (Display Systems Biotech) at $65^{\circ} \mathrm{C}$ for $2 \mathrm{~h}$. The RFDD-PCR template was completed by ligating the digest to a standard adaptor and an EP adaptor containing an extension protection group at $37^{\circ} \mathrm{C}$ for $3 \mathrm{~h}$ using T4 DNA ligase 

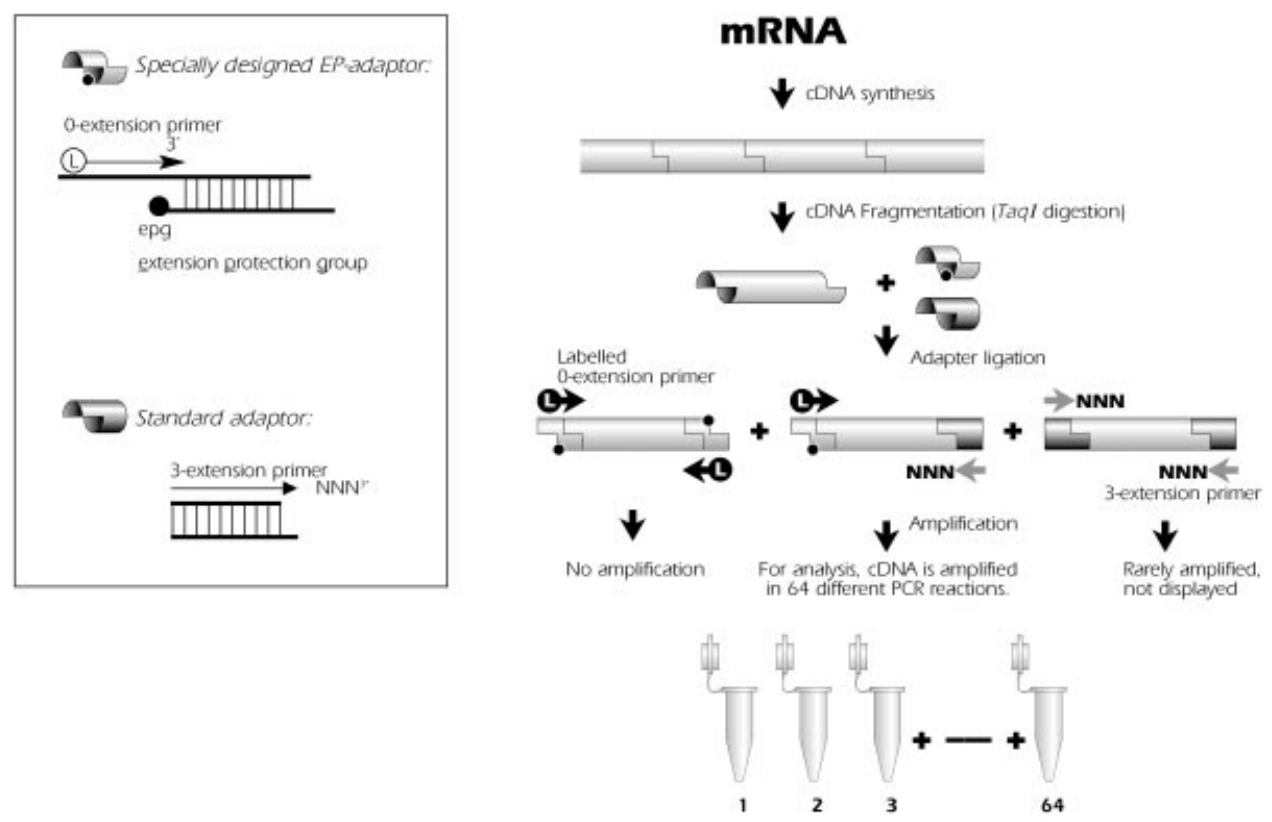

Fig. 1. Schematic outline of the RFDD-PCR technology. After synthesis from total RNA, the double-stranded CDNA is digested with Taql. Following digestion, two specially designed DNA adaptors (see enlargement in box) are ligated to the cDNA fragments. Adaptor ligation has three possible outcomes. One of the adaptors, called the EP adaptor, lacks part of the complementary strand which has an 'extension protection group' on its 3'-end preventing the polymerase from filling in the complementary strand. The extension protection group on the EP adaptor prevents amplification of cDNA fragments that have EP adaptors on both ends. Each of the 64 PCR reactions uses a labelled 0-extension $5^{\prime}$-primer that anneals to the EP adaptor, and one of a set of 64 specific 3-extension primers that anneal to the junction between the standard adaptor and the cDNA insert. Only restriction fragments with one of each adaptor will be amplified and visualized. Fragments with two EP adaptors will not be amplified, whilst fragments with both standard adaptors will only be rarely amplified and not visualized.

(Display Systems Biotech). The sequences of the standard adaptor were as follows: 5'-GCGATGAGTCCTGAC-3' (upper strand) and 5'-CGGTCAGGACTCAT-3' (lower strand). The sequences of the EP adaptor were: $5^{\prime}$-ACTGGTCTCGTAGACTGCGTACC-3' (upper strand) and 5'-PO ${ }_{4}$-CGGGTACGCAGTddC-3' (lower strand). The $5^{\prime}$ end was modified with a phosphate group whilst the last nucleotide in the $3^{\prime}$ end was a dideoxynucleotide (the so-called extension protection group). The incubation was carried out at $37^{\circ} \mathrm{C}$ and not the standard $16^{\circ} \mathrm{C}$ to maintain the TaqI endonuclease activity during the ligation. This prevented religation of cDNA TaqI fragments, but not adaptor ligation, since the latter did not reestablish the TaqI site.

The template was PCR amplified using a 0-extension primer complementary to the EP adaptor in combination with a 3extension primer recognizing the standard adaptor and the three nucleotides adjacent to the TaqI site. The 0 -extension primer was either fluorescently labelled with Cy5 (Display Systems Biotech) or kinase-labelled with $\left[\gamma^{3}{ }^{33} \mathrm{P}\right] \mathrm{dATP}$ [3000 $\left.\mathrm{Ci} \mathrm{mmol}^{-1}\left(1 \cdot 11 \times 10^{14} \mathrm{~Bq} \mathrm{mmol}^{-1}\right) ; \mathrm{ICN}\right]$. All PCR reactions were carried out in a $20 \mu \mathrm{l}$ volume using $0 \cdot 2 \mu \mathrm{l}$ template and standard concentration of dNTPs and primers, using the following PCR-amplification profile: initial denaturation $94{ }^{\circ} \mathrm{C}, 1 \mathrm{~min}$, then for the first 10 cycles: $94{ }^{\circ} \mathrm{C}$, $30 \mathrm{~s} ; 60^{\circ} \mathrm{C}$ with touchdown by $0.5^{\circ} \mathrm{C}$ for each cycle until $55^{\circ} \mathrm{C}$ is reached; $72{ }^{\circ} \mathrm{C}, 1 \mathrm{~min}$, and for the last 25 cycles: $94{ }^{\circ} \mathrm{C}, 30 \mathrm{~s} ; 55^{\circ} \mathrm{C}, 30 \mathrm{~s} ; 72{ }^{\circ} \mathrm{C}, 1 \mathrm{~min}$.

The complete analysis was performed using fluorescence labelling. For each template, 32 PCR reactions using the Cy5labelled 0-extension primer in combination with the 32 different 3-extension primers (NNA/G or NNC/T) were performed. The PCR products were resolved on a standard $6 \%$ polyacrylamide sequencing gel by the ALF Express DNA sequencer (Amersham Pharmacia Biotech). The profiles were analysed using the Fragment Manager program (Amersham Pharmacia Biotech), and fragment sizes were calculated from the Cy5-labelled size marker, Sizer 50-500 (Amersham Pharmacia Biotech). Reactions where modulations were detected were amplified again using isotopic labelling of the 0extension primer. The isotopic samples were run on the ALF Express DNA sequencer and dried onto Whatman paper. Bands corresponding to those indicated by the fluorescencebased analysis to be differentially expressed were identified on the autoradiogram. The dried gel was lined up with markings on the film and the fragments were excised from the gel. The gene fragments were eluted and reamplified using the same PCR conditions and primers as in the initial PCR reaction.

PCR fragment cloning and sequencing. It was generally possible to obtain sequence directly from approximately $30 \%$ of the reamplified PCR products, as judged from these and other experiments with L. monocytogenes. Other fragments were cloned prior to sequencing. PCR fragments were cloned using the Original TA Cloning kit (Invitrogen) according to the manufacturer's instructions. The cloned inserts were PCR amplified and the products were purified with the QIAquick PCR Purification kit (Qiagen) and sequenced with the Thermo Sequenase fluorescent-labelled primer cycle sequencing kit 

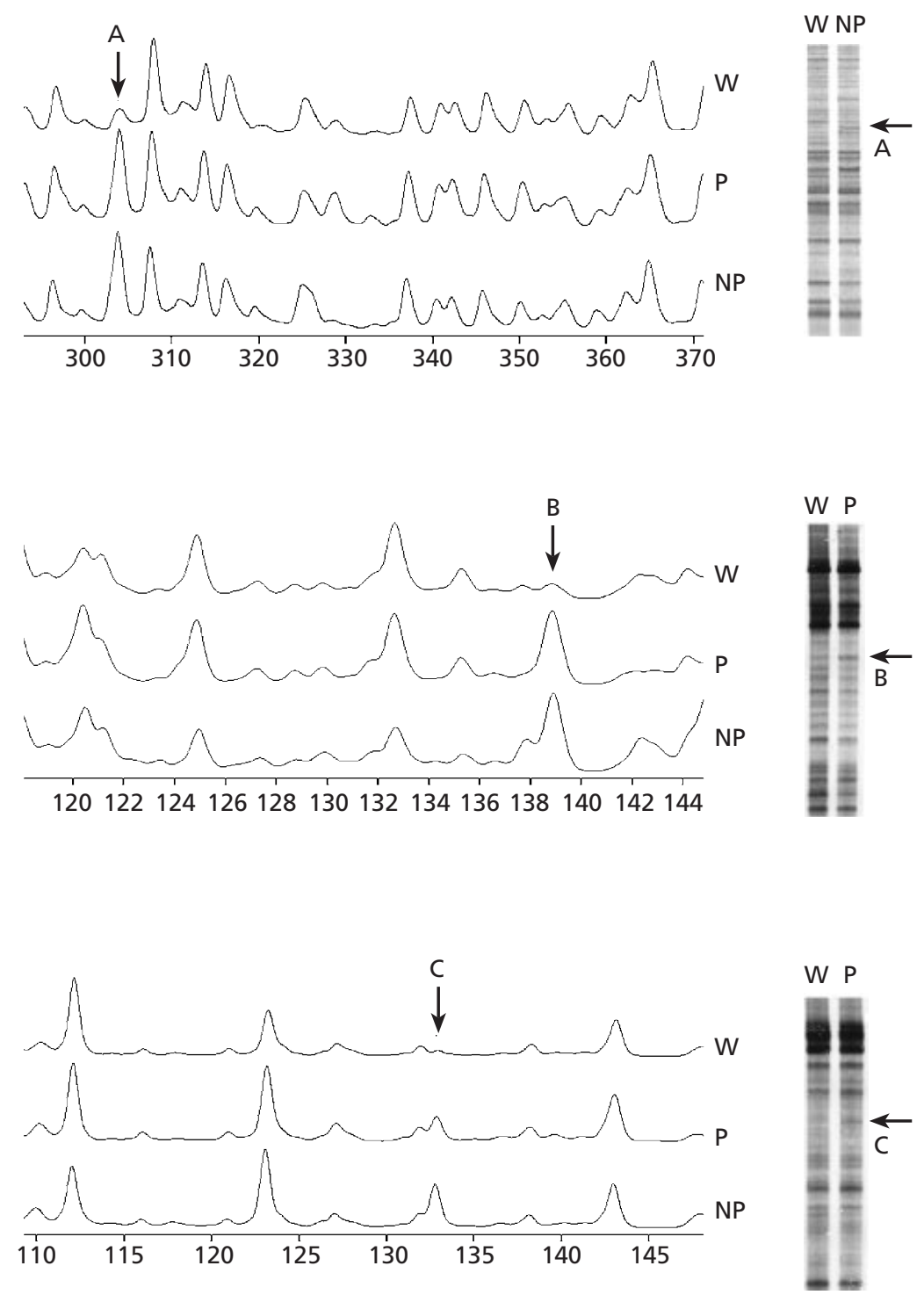

Fig. 2. Fluorescent and isotopic RFDD-PCR analysis of $L$. monocytogenes 412 resistant to pediocin. The left of the figure shows the identification of the three fragments, A, B

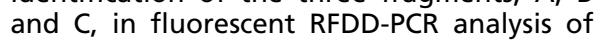
the wild-type isolate $L$. monocytogenes 412 (W) and the two independent pediocinresistant mutants $L$. monocytogenes $412 \mathrm{P}(\mathrm{P})$ and 412NP (NP). The electrophoresis run time is shown in minutes. The right of the figure shows the subsequent isotopic analysis and identification of the bands for gel excision.
(Amersham Pharmacia Biotech) on the ALF Express DNA sequencer. The sequences of the TaqI restriction fragments were deposited in the EMBL database under the following accession numbers : fragment A (292 bp), AJ251202; fragment B (103 bp), AJ251203; fragment C (94 bp), AJ251204. Translated amino acid homology searches were made with the BLASTX program (Altschul et al., 1990) to the translated GenBank release 111.0, PIR release 59.0 and SWISS-PROT release 37.0 databases.

Northern hybridization. Equal amounts of RNA were electrophoresed on a $1 \%$ agarose gel by the procedure of Pellé \& Murphy (1993). The RNA was transferred to a Hybond-N membrane (Amersham Pharmacia Biotech) by capillary transfer, and UV cross-linked at $1200 \mathrm{~W}$. Probes labelled with $[\alpha-$ ${ }^{32} \mathrm{P}$ ]dATP (3000 $\mathrm{Ci} \mathrm{mmol}{ }^{-1}$, Amersham Pharmacia Biotech) were prepared with the Multiprime DNA labelling system (Amersham Pharmacia Biotech) from QIAquick-purified (Qiagen) PCR products. Unincorporated radioactivity was removed on Nick columns (Amersham Pharmacia Biotech). Hybridization was visualized by the STORM 840 PhosphorImager (Molecular Dynamics). Membranes were stripped and reprobed up to three times.

\section{RESULTS}

\section{Use of RFDD-PCR for analysis of L. monocytogenes gene expression}

The RFDD-PCR technology, which is outlined and described in Fig. 1, relates gene expression to the concentration of the corresponding cDNA amplified by PCR, as in traditional DD-PCR. Double-stranded cDNA was synthesized from total RNA and digested with the TaqI restriction enzyme. Following digestion and adaptor ligation, the template was amplified using a 0 extension primer combined with a 3-extension primer. The 3-extension primer binds to the regular adaptor and extends 3 bases (NNN) past the adaptor junction into the cDNA fragment. These three bases determined which cDNAs were amplified in a specific reaction. Thus, each PCR reaction only amplified a specific subset of cDNA fragments that had a specific three-base sequence upstream of the TaqI restriction site. To amplify all subsets, which provides a complete cross- 
section of all the expressed sequences, only 64 (i.e. $4^{3}$ ) different primers are necessary. Visualization of the PCR products was obtained by labelling of the 0 -extension primer. Fragments with two 3-extension primers will be amplified if the three-base extension matches the sequence adjacent to the TaqI restriction sites at both ends, but will not be labelled by the 0 -extension primer. Such non-visualized background PCR products will only constitute $1 / 64$ of the visualized PCR products.

Initial experiments showed that individual use of the 3extension primers resulted in relatively few RFDD-PCR fragments. The analysis was therefore carried out with primers degenerate in the third position, NNA/G or $\mathrm{NNC} / \mathrm{T}$, giving a $50 \%$ workload reduction. The amplifications contained on average 50-70 fragments (between 10 and 100 fragments), the majority of which were under $400 \mathrm{bp}$, the largest being $770 \mathrm{bp}$. The total of approximately 1500 fragments should give a reasonable coverage of the mRNA population, assuming an estimate of 400-900 different mRNA molecules in bacterial cells (Neidhardt et al., 1990).

Some reactions contained one fragment at extremely high concentrations. Comparison of the size and 3extension of these TaqI fragments to published $L$. monocytogenes rRNA gene sequences indicated that they originated from the ribosomal RNA genes.

\section{Isolation of differentially expressed gene fragments}

The purpose of the analysis was to identify constitutive changes in gene expression following spontaneous development of pediocin resistance. Therefore, RNA for RFDD-PCR analysis was isolated after growth without selection of the wild-type strain L. monocytogenes 412 and the two independent, pediocin-resistant mutants $L$. monocytogenes 412P and 412NP. Two independent mutants were used as an inherent control in the experiment in order to avoid false-positive results, as changes seen in both strains would be expected to be due to a common resistance mechanism.

The RFDD-PCR products were initially analysed with the Cy5-labelled 0-extension primer (Fig. 2). This enabled a quantitative measure of differences in expression by comparison of peak areas. The 32 fluorescent profiles of the three strains were compared. Since the PCR products contain approximately $40 \mathrm{bp}$ adaptor sequence, only fragments longer than $100 \mathrm{bp}$ (e.g. TaqI restriction fragments longer than $60 \mathrm{bp}$ ) and having at least fivefold differences in expression were considered in the analysis. In total, ten fragments met the above criteria. Six fragments having changes in only one of the two mutants were not analysed further.

The remaining four fragments all had increased expression in the mutant strains. The corresponding PCR reactions were run again with radioactively labelled 0 extension primer. Three of the fragments were successfully identified on the radiogram (Fig. 2). Excision from the gel, DNA elution and fluorescent reamplification resulted in PCR products of the same size

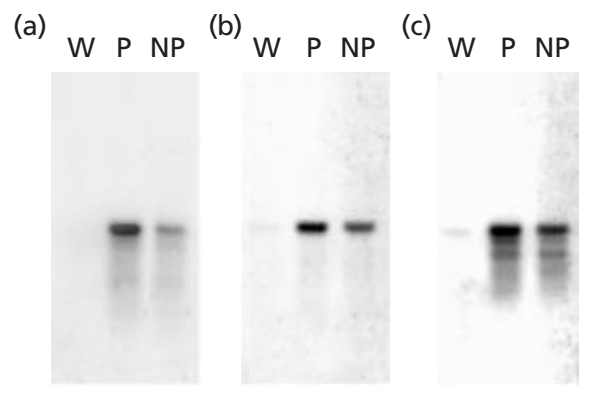

Fig. 3. Northern blot verification of differential expression. Total RNA from the wild-type isolate L. monocytogenes 412 (W) and the two independent pediocin-resistant mutants $L$. monocytogenes 412P (P) and 412NP (NP) was hybridized employing PCR products of the cloned fragments $A, B$ and $C$ as probes. All three fragments had increased expression in both mutant strains.

as the originally identified peaks $( \pm 1 \mathrm{bp})$. The PCR fragment sizes were: A, $326 \mathrm{bp}$;, $136 \mathrm{bp}$; and $\mathrm{C}$, $127 \mathrm{bp}$.

\section{Northern verification of differential expression}

To obtain sufficiently pure hybridization probes for Northern blots, the three reamplified PCR fragments were cloned. The cloned fragments were amplified by PCR and used as probes in hybridizations to new RNA preparations from the three strains cultured without selection. The three fragments hybridized strongly to RNA from the two pediocin-resistant mutants, but not from the wild-type strain, as shown in Fig. 3. All three hybridized to a transcript of the same size.

Northern blots of 10 additional independent pediocinresistant mutants of L. monocytogenes 412 , isolated at varying $\mathrm{pH}(6.5$ and 5.5$)$, added salt $(0 \%$ and $6 \%)$ and temperature $\left(10\right.$ and $\left.30^{\circ} \mathrm{C}\right)$, were performed using fragments $\mathrm{A}$ and $\mathrm{C}$ as probes (data not shown). All the mutants had increased expression of the corresponding transcript. Fragment B was not tested because it originates from the same gene as fragment $\mathrm{C}$ (see below).

\section{Amino acid homology of the overexpressed fragments}

The cloned fragments were sequenced and databases were searched for amino acid homology. All three had homology to PTS for sugar uptake and utilization, with highest homology to $\beta$-glucoside-specific systems. The proteins conveying uptake and concomitant phosphorylation, called the permease or enzyme II, have been divided into families based on domain organization and homology, with over $25 \%$ amino acid identity within families (Postma et al., 1993). The $\beta$-glucoside- and sucrose-specific permeases constitute a subclass of the glucose class. The $\beta$-glucoside subgroup typically have a IIBCA domain structure, where IIC is the membranebound domain undertaking substrate binding and translocation, and IIA and IIB are hydrophilic domains 


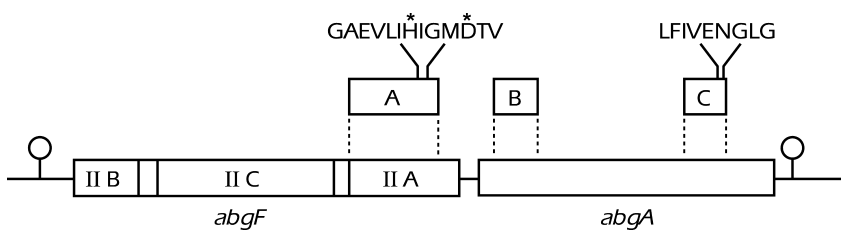

Fig. 4. Homology of the overexpressed fragments to the $\beta$ glucoside-specific PTS system abgAF. The abgAF operon from Clostridium longisporum encodes the putative enzyme II AbgF (616 aa) and the putative phospho- $\beta$-glucosidase AbgA (473 aa) (Brown \& Thomson, 1998). The regions corresponding to the three fragments with verified overexpression in pediocinresistant mutants of $L$. monocytogenes 412 are depicted. Fragment A contained the IIA phosphorylation motif (Brown \& Thomson, 1998) with the histidyl and aspargyl catalytic residues marked by asterisks (Schnetz et al., 1990). Fragment B corresponded to a variable domain and fragment $C$ contained the glycosyl hydrolase motif (Brown \& Thomson, 1998).

involved in phosphoryl group transfer (Lengeler et al., 1994). The permeases are in most cases co-transcribed with the downstream phospho- $\beta$-glucosidase and the expression is regulated by catabolite repression mediated by the general PTS proteins, and specific induction by the $\beta$-glucoside substrates which prevents negative regulation by IIAB (Rutberg, 1997; Stülke et al., 1998).

The three cloned fragments had highest homology to abgAF from Clostridium longisporum (Brown \& Thomson, 1998). The corresponding regions are shown in Fig. 4. Fragment A, comprising 96 translated amino acids, had $71 \%$ identity to the C-terminal region of the putative enzyme II, AbgF, encompassing the IIA phosphorylation motif (Brown \& Thomson, 1998) with the histidyl and aspargyl catalytic residues (Schnetz et al., 1990). Fragment B (33 aa) had $66 \%$ identity to an $\mathrm{N}$ terminal domain of the putative phospho- $\beta$-glucosidase AbgA. Fragment C (30 aa) had 73\% identity to the Cterminus of $\mathrm{AbgA}$, including the glycosyl hydrolase motif LFIVENGLG (Brown \& Thomson, 1998).

Fragments $\mathrm{A}$ and $\mathrm{C}$ had extensive homology to other PTS systems. The translated sequence A had 52-60\% identity to $\beta$-glucoside-specific permeases from Bacillus subtilis (accession no. P40739), Escherichia coli (P08722), Erwinia crysanthemi (P26207) and Klebsiella oxytoca (U61727), 48-55\% identity to sucrose-specific permeases, $46-52 \%$ identity to other glucose-class enzyme II proteins and 38-50\% identity to other classes. There was only $48 \%$ identity to the $\beta$-glucoside-specific BvrB from L. monocytogenes (Brehm et al., 1999). However, this system has an atypical organization, as the permease is not followed by a downstream phospho$\beta$-glucosidase, which could indicate a more distant relationship. Fragment $\mathrm{C}$ had $68-82 \%$ identity to phospho- $\beta$-glucosidases from Esc. coli (P11988), K. oxytoca (Q48409), Lactobacillus plantarum (Y15954), Erw. crysanthemi (P26206), B. subtilis (S47175) and Esc. coli (P24240), and $65-72 \%$ identity to $\beta$-galactosidases.

Translation of fragment $\mathrm{B}$ only showed homology to two additional phospho- $\beta$-glucosidases, $63 \%$ and $52 \%$ identity, respectively, to ArbB from Erw. crysanthemi (P26206) and CasB from K. oxytoca (Q48409). Alignment of the phospho- $\beta$-glucosidases homologous to fragment $\mathrm{C}$ showed that fragment $\mathrm{B}$ corresponded to a $\mathrm{N}$-terminal variable domain. This would explain the limited homology found for fragment $\mathrm{B}$, compared to fragments $\mathrm{A}$ and $\mathrm{C}$ encompassing motif domains.

\section{DISCUSSION}

\section{RFDD-PCR as a prokaryotic gene expression technology}

There are currently a number of different technologies available for studying gene expression in both eukaryotic and prokaryotic organisms (Handfield \& Levesque, 1999; Zhang et al., 1998) and several aspects require consideration in the choice of method. For instance, it should be clarified how reproducible the method is, what comprehensive coverage the method provides, whether the method is dependent on the organism being studied and, finally, whether the method can detect low-abundance transcripts. Although still widely used, the first differential display method (Liang \& Pardee, 1992), which was designed to give a comprehensive coverage of the genetic profile of a cell, is limited to eukaryotic organisms due to the dependence on the polyA tail of the messenger. Furthermore, the technology suffered from reproducibility problems (Debouck, 1995) due to the very low-stringency PCR conditions required for unspecific annealing of the arbitrary primers.

The RFDD-PCR technology presented here has proved to be a strong approach for the identification of differentially expressed genes in Listeria. All three gene fragments identified as being differentially expressed in L. monocytogenes 412 following development of pediocin resistance were, by Northern blots, shown to have increased expression in the resistant mutants compared to the wild-type strain. The technology is simple in its concept and can be generally applied to all bacterial species. In addition, the method had good reproducibility and coverage, and enabled simultaneous monitoring of expression profiles from several samples. There is some debate concerning the sensitivity of DD technologies to rare mRNAs, and no data relating to prokaryotic RNA have been published. It is estimated that a typical mammalian cell expresses around 1000030000 different mRNA, whereas prokaryotes are estimated to express only around 400-900 mRNA molecules (Neidhardt et al., 1990). It has recently been found that a cDNA amplified fragment length polymorphism technology, related to RFDD-PCR, can detect 1 in 100000 expressed mRNAs (Shimkets et al., 1999). It can thus be anticipated that RFDD-PCR applied to prokaryotes will have comparative sensitivity, which would be sufficient since the bacterial RNA used in the analysis is much less complex.

Recently, cDNA array hybridization techniques have become increasingly used for the study of eukaryotic 
and prokaryotic gene expression (for review see Zhang et al., 1998). In micro-array analysis, gene fragments are spotted down on a surface and different probes prepared from RNA samples are hybridized onto the cDNA arrays to visualize differences in expression levels. This procedure is fast and may in the near future be the method of choice to study differential expression in prokaryotes. The main restriction to the application of micro-arrays is the requirement of access to extensive genome sequence information in order to synthesize the gene fragment arrays for the specific organism. RFDDPCR gives a strong alternative to these technologies, due to the possibility of acquiring a comprehensive picture of the genetic profile of any prokaryote or eukaryote where limited genome information is available.

\section{Pediocin-resistant $L$. monocytogenes 412 mutants had increased expression of a putative PTS}

The observed homology strongly indicated that the three gene fragments with verified overexpression in pediocin-resistant L. monocytogenes 412 mutants originated from a PTS specific for $\beta$-glucoside uptake and utilization: fragment $\mathrm{A}$ was homologous to $\beta$ glucoside-specific enzyme II permeases and fragments B and $\mathrm{C}$ were homologous to phospho- $\beta$-glucosidases. The three fragments hybridized to transcripts of the same size, indicating that the two proteins could be cotranscribed as in other systems (Rutberg, 1997), as illustrated in Fig. 4.

Recently, burB encoding an enzyme II specific for $\beta$ glucosides in L. monocytogenes was reported (Brehm et al., 1999). The $4 \mathrm{~kb}$ operon burABC had an unusual organization. bvrA encoded a typical antiterminator protein, but $b v r C$ encoded a putative ADP-ribosylglycohydrolase, and not the usual $\beta$-glucosidase. The virulence genes of L. monocytogenes are regulated by catabolite repression (Milenbachs et al., 1997), and repressed by $\beta$-glucosides (Park \& Kroll, 1993; Park, 1994). Disruption of bvr did not affect $\beta$-glucoside utilization, but abolished virulence gene repression by cellobiose and salicin but not arbutin (Brehm et al., 1999). Obviously, other system(s) also mediate $\beta$ glucoside uptake and virulence gene regulation by arbutin. These functions could be accomplished by the system containing fragments $\mathrm{A}, \mathrm{B}$, and C.

In addition, PTS systems for glucose and fructose have been identified in L. monocytogenes (Mitchell et al., 1993; Parker \& Hutkins, 1997). Glucose uptake in $L$. monocytogenes was sensitive to pediocin JD (identical to pediocin PA-1) (Christensen \& Hutkins, 1994). Nisin and pediocin JD inhibited the glucose PTS through depletion of intracellular metabolites including phosphoenolpyruvate, which is essential for PTS activity (Waite et al., 1998). In phosphoenolpyruvatesupplemented assays, nisin actually caused stimulation of the glucose PTS, while pediocin maintained the inhibitory effect (Waite \& Hutkins, 1998). The authors concluded that nisin solely inhibited glucose uptake because of efflux of intracellular metabolites, while the inhibition by pediocin also involved another, unknown mechanism.

The consistent overexpression of the gene fragments in a total of 12 independent pediocin-resistant mutants, isolated under conditions that influence the cell envelope constitution, clearly suggests that increased expression of the putative $\beta$-glucoside-specific PTS system is involved in a general mechanism mediating pediocin resistance. This could either be due to a direct effect, for example if the membrane-bound enzyme II binds pediocin, thereby preventing its detrimental effect either on the glucose PTS or by pore formation, or it could be a regulatory side-effect of the actual resistance mechanism. Current work is aimed at investigating whether the observed consistent increase in $\beta$-glucoside-specific PTS expression is directly linked to pediocin resistance.

\section{ACKNOWLEDGEMENTS}

This work was supported by the Danish FØTEK 2 programme (93s-2469-å95-00064) and the Danish Bacon and Meat Council. The technical assistance of Lene Gertman and Lotte Rasmussen is highly appreciated. The authors thank Hanne Ingmer for helpful discussions and K. Bjørn Rechinger for critical reading of the manuscript.

The RFDD-PCR technology is covered by PATENT PCT/ DK98/00186.

\section{REFERENCES}

Abu, K. Y. \& Pederson, L. L. (1996). The use of differential displayPCR to isolate and characterize a Legionella pneumophila locus induced during the intracellular infection of macrophages. Mol Microbiol 21, 543-556.

Altschul, S. F., Gish, W., Miller, W., Myers, E. W. \& Lipman, D. J. (1990). Basic local alignment search tool. J Mol Biol 215, 403-410.

Arnau, J. \& Sørensen, K. I. (1997). The isolation of novel heat shock genes in Lactococcus lactis using RNA subtractive hybridization. Gene 188, 229-234.

Bachem, C. W., van der Hoeven, R. S., de Bruijn, S.M., Vreugdenhil, D., Zabeau, M. \& Visser, R. G. (1996). Visualization of differential gene expression using a novel method of RNA fingerprinting based on AFLP : analysis of gene expression during potato tuber development. Plant J 9, 745-753.

Brehm, K., Ripio, M. T., Kreft, J. \& Vazquez-Boland, J. A. (1999). The bur locus of Listeria monocytogenes mediates virulence gene repression by beta-glucosides. J Bacteriol 181, 5024-5032.

Brötz, H., Josten, M., Wiedemann, I., Schneider, U., Götz, F., Bierbaum, G. \& Sahl, H. G. (1998). Role of lipid-bound peptidoglycan precursors in the formation of pores by nisin, epidermin and other lantibiotics. Mol Microbiol 30, 317-327.

Brown, G. D. \& Thomson, J. A. (1998). Isolation and characterisation of an aryl-beta-D-glucoside uptake and utilisation system $(a b g)$ from the gram-positive ruminal Clostridium species C. longisporum. Mol Gen Genet 257, 213-218.

Chen, Y., Shapira, R., Eisenstein, M. \& Montville, T. J. (1997). Functional characterization of pediocin PA-1 binding to liposomes in the absence of a protein receptor and its relationship to a predicted tertiary structure. Appl Environ Microbiol 63, 524-531.

Chikindas, M. L., Garcia-Garcera, M. J., Driessen, A. J., Ledeboer, 
A. M., Nissen-Meyer, J., Nes, I. F., Abee, T., Konings, W. N. \& Venema, G. (1993). Pediocin PA-1, a bacteriocin from Pediococcus acidilactici PAC1.0, forms hydrophilic pores in the cytoplasmic membrane of target cells. Appl Environ Microbiol 59, 3577-3584.

Christensen, D. P. \& Hutkins, R. W. (1994). Glucose uptake by Listeria monocytogenes Scott A and inhibition by pediocin JD. Appl Environ Microbiol 60, 3870-3873.

Crandall, A. D. \& Montville, T. J. (1998). Nisin resistance in Listeria monocytogenes ATCC 700302 is a complex phenotype. Appl Environ Microbiol 64, 231-237.

Davies, E. A., Falahee, M. B. \& Adams, M. R. (1996). Involvement of the cell envelope of Listeria monocytogenes in the acquisition of nisin resistance. J Appl Bacteriol 81, 139-146.

Debouck, C. (1995). Differential display or differential dismay. Curr Opin Biotechnol 6, 597-599.

Ennahar, S., Sonomoto, K. \& Ishizaki, A. (1999). Class IIa bacteriocins from lactic acid bacteria: antibacterial activity and food preservation. J Biosci Bioeng 87, 705-716.

Fislage, R., Berceanu, M., Humboldt, Y., Wendt, M. \& Oberender, H. (1997). Primer design for a prokaryotic differential display RTPCR. Nucleic Acids Res 25, 1830-1835.

Fleming, J. T., Yao, W. H. \& Sayler, G. S. (1998). Optimization of differential display of prokaryotic mRNA: application to pure culture and soil microcosms. Appl Environ Microbiol 64, 3698-3706.

Goulhen, F., Hafezi, A., Uitto, V. J., Hinode, D., Nakamura, R., Grenier, D. \& Mayrand, D. (1998). Subcellular localization and cytotoxic activity of the GroEL-like protein isolated from Actinobacillus actinomycetemcomitans. Infect Immun $\mathbf{6 6}$, 5307-5313.

Handfield, M. \& Levesque, R. C. (1999). Strategies for isolation of in vivo expressed genes from bacteria. FEMS Microbiol Rev 23, 69-91.

Kullen, M. J. \& Klaenhammer, T. R. (1999). Identification of the $\mathrm{pH}$-inducible, proton-translocating $\mathrm{F}_{1} \mathrm{~F}_{0}$-ATPase (atpBEFHAGDC) operon of Lactobacillus acidophilus by differential display: gene structure, cloning and characterization. Mol Microbiol 33, 1152-1161.

Kustu, S., Santero, E., Keener, J., Popham, D. \& Weiss, D. (1989). Expression of sigma $54(n t r A)$-dependent genes is probably united by a common mechanism. Microbiol Rev 53, 367-376.

Lengeler, J. W., Jahreis, K. \& Wehmeier, U. F. (1994). Enzymes II of the phospho enol pyruvate-dependent phosphotransferase systems: their structure and function in carbohydrate transport. Biochim Biophys Acta 1188, 1-28.

Liang, P. \& Pardee, A. B. (1992). Differential display of eukaryotic messenger RNA by means of the polymerase chain reaction. Science 257, 967-971.

Maisnier-Patin, S. \& Richard, J. (1996). Cell wall changes in nisinresistant variants of Listeria innocua grown in the presence of high nisin concentrations. FEMS Microbiol Lett 140, 29-35.

Mazzotta, A. S. \& Montville, T. J. (1997). Nisin induces changes in membrane fatty acid composition of Listeria monocytogenes nisin-resistant strains at 10 degrees $\mathrm{C}$ and 30 degrees C. J Appl Microbiol 82, 32-38.

Milenbachs, A. A., Brown, D. P., Moors, M. \& Youngman, P. (1997). Carbon-source regulation of virulence gene expression in Listeria monocytogenes. Mol Microbiol 23, 1075-1085.

Ming, X. \& Daeschel, M. A. (1995). Correlation of cellular phospholipid content with nisin resistance of Listeria monocytogenes Scott A. J Food Prot 58, 416-420.
Mitchell, W. J., Reizer, J., Herring, C., Hoischen, C. \& Saier, M. H., Jr (1993). Identification of a phosphoenolpyruvate:fructose phosphotransferase system (fructose-1-phosphate forming) in Listeria monocytogenes. J Bacteriol 175, 2758-2761.

Montville, T. J. \& Chen, Y. (1998). Mechanistic action of pediocin and nisin: recent progress and unresolved questions. Appl Microbiol Biotechnol 50, 511-519.

Neidhardt, F. C., Ingraham, J. L. \& Schaechter, M. (1990). Physiology of the Bacterial Cell: a Molecular Approach. Sunderland, MA: Sinaur Associates, Inc.

Nissen-Meyer, J. \& Nes, I. F. (1997). Ribosomally synthesized antimicrobial peptides: their function, structure, biogenesis, and mechanism of action. Arch Microbiol 167, 67-77.

Park, S. F. (1994). The repression of listeriolysin O expression in Listeria monocytogenes by the phenolic beta-D-glucoside, arbutin. Lett Appl Microbiol 19, 258-260.

Park, S. F. \& Kroll, R. G. (1993). Expression of listeriolysin and phosphatidylinositol-specific phospholipase $\mathrm{C}$ is repressed by the plant-derived molecule cellobiose in Listeria monocytogenes. Mol Microbiol 8, 653-661.

Parker, C. \& Hutkins, R. W. (1997). Listeria monocytogenes Scott A transports glucose by high-affinity and low-affinity glucose transport systems. Appl Environ Microbiol 63, 543-546.

Pellé, R. \& Murphy, N. B. (1993). Northern hybridization: rapid and simple electrophoretic conditions. Nucleic Acids Res 21, 2783-2784.

Postma, P. W., Lengeler, J. W. \& Jacobson, G. R. (1993). Phosphoenolpyruvate:carbohydrate phosphotransferase systems of bacteria. Microbiol Rev 57, 543-594.

Rasch, M. \& Knøchel, S. (1998). Variations in tolerance of Listeria monocytogenes to nisin, pediocin PA-1 and bavaricin A. Lett Appl Microbiol 27, 275-278.

Robichon, D., Gouin, E., Debarbouille, M., Cossart, P., Cenatiempo, Y. \& Hechard, Y. (1997). The rpoN (sigma54) gene from Listeria monocytogenes is involved in resistance to mesentericin Y105, an antibacterial peptide from Leuconostoc mesenteroides. J Bacteriol 179, 7591-7594.

Rutberg, B. (1997). Antitermination of transcription of catabolic operons. Mol Microbiol 23, 413-421.

Sahl, H. G. \& Bierbaum, G. (1998). Lantibiotics: biosynthesis and biological activities of uniquely modified peptides from grampositive bacteria. Annu Rev Microbiol 52, 41-79.

Schnetz, K., Sutrina, S. L., Saier, M. H., Jr \& Rak, B. (1990). Identification of catalytic residues in the beta-glucoside permease of Escherichia coli by site-specific mutagenesis and demonstration of interdomain cross-reactivity between the beta-glucoside and glucose systems. J Biol Chem 265, 13464-13471.

Shepard, B. D. \& Gilmore, M. S. (1999). Identification of aerobically and anaerobically induced genes in Enterococcus faecalis by random arbitrarily primed PCR. Appl Environ Microbiol 65, 1470-1476.

Shimkets, R. A., Lowe, D. G., Tai, J. T. \& 17 other authors (1999). Gene expression analysis by transcript profiling coupled to a gene database query. Nat Biotechnol 17, 798-803.

Stülke, J., Arnaud, M., Rapoport, G. \& Martin-Verstraete, I. (1998). PRD - a protein domain involved in PTS-dependent induction and carbon catabolite repression of catabolic operons in bacteria. Mol Microbiol 28, 865-874.

Verheul, A., Russell, N. J., Van'T, H. R., Rombouts, F. M. \& Abee, T. (1997). Modifications of membrane phospholipid composition in nisin-resistant Listeria monocytogenes Scott A. Appl Environ Microbiol 63, 3451-3457. 
Waite, B. L. \& Hutkins, R. W. (1998). Bacteriocins inhibit glucose PEP:PTS activity in Listeria monocytogenes by induced efflux of intracellular metabolites. J Appl Microbiol 85, 287-292.

Waite, B. L., Siragusa, G. R. \& Hutkins, R. W. (1998). Bacteriocin inhibition of two glucose transport systems in Listeria monocytogenes. J Appl Microbiol 84, 715-721.
Zhang, J. S., Duncan, E. L., Chang, A. C. \& Reddel, R. R. (1998). Differential display of mRNA. Mol Biotechnol 10, 155-165.

Received 21 December 1999; revised 20 February 2000; accepted 28 February 2000. 